\title{
Oral rehabilitation of a patient with ankylosing spondylitis and orofacial pain: A case report
}

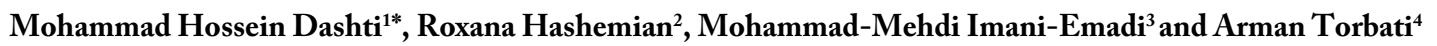 \\ ${ }^{1}$ Clinical Associate Professor, Postdoctoral Prosthodontics, Department of Restorative Sciences and Biomaterials, Boston University Henry M. Goldman School of \\ Dental Medicine, 100 East Newton Street, Boston, Ma 02118, USA \\ ${ }^{2}$ Clinical Instructor, Department of General Dentistry, Boston University Henry M. Goldman School of Dental Medicine, 100 East Newton Street, Boston, Ma \\ 02118, USA \\ ${ }^{3}$ Advanced resident, Nova Southeastern University College of Dentistry, Postdoctoral Prosthodontics, 2826S University Drive, Apt\# 3104 Davie, FL 33328, USA \\ ${ }^{4}$ Diplomate American Board of Prosthodontists. Clinical Associate Professor, University of Southern California. 9911 West Pico Boulevard suite 950. Los Angeles, \\ Ca 90035, USA
}

\begin{abstract}
Oral rehabilitation of patients with skeletal disorders requires important considerations and precautions. Ankylosing spondylitis (AS) is an inflammatory disease of the axial skeleton which can also affect the peripheral joints including the temporomandibular joint (TMJ). Patients with AS can suffer from skeletal pain during long dental appointments. Local, systemic, and psychological factors in this population can inadvertently complicate the diagnosis and treatment of their oral conditions. A case of a patient with AS and in need of oral rehabilitation is reported.
\end{abstract}

\section{Introduction}

Ankylosing spondylitis (AS) is a chronic, usually progressive, inflammatory disease of the axial skeleton often affecting the spine and sacroiliac joints $[1,2]$. Prevalence of $0.1-1 \%$ of general population is reported, with male dominancy of 3:1 [2-4]. Typically, a young 20-40 years old male person is affected. Average age of diagnosis is around 23-28 years with a 5.3-11.4 years delay from the onset of symptoms [4-6]. A strong genetic predisposition with environmental modulation is described. More than $92 \%$ of cases with AS are human leukocyte antigen (HLA)-B27 positive. This varies in different races and geographical locations [3]. Notably, only 5\% of HLA-B27 positive population progress to AS [4,7]. HLA-B27 is also associated with other inflammatory diseases classified as Spondyloarthropathies. A common initial complaint is a radiating low back pain to the buttocks that is alleviated by non-steroidal anti-inflammatory drugs (NSAIDs) and exercising [8]. On examination, sacroiliac joints are tender and pain radiates to the back thigh [3].

The treating dental professional should be suspicious of AS when a patient shows the symptoms of a painful hypo-mobile back joint with no history of trauma and neck or back complaints, and should consider a rheumatologist consult $[9,10]$.

A key pathologic change is an ongoing inflammatory process at ligaments and tendons insertion sites with ultimate fibrosis and ossification [11]. Progressively, along with ossification induction at fibrous annulus of vertebrae, a bony bridge forms and fusion occurs. This adversely limits spinal flexion and extension that become worsen as disease progresses [3]. Peripheral joint involvement occurs in 10$30 \%$ of patients and may occur in an irregular fashion [1].

The involvement of the temporomandibular joint (TMJ) in AS has not been widely recognized, and its prevalence is disputed $[1,12]$.
Frequency of TMJ involvement in patients with AS has varied from $4 \%$ to $35 \%$. It is more common in men and produces generalized stiffness in involved joints $[1,13]$. It is felt that most TMJ symptoms related to AS may be as a consequence of muscle spasm and postural imbalance [4].

TMJ may be involved with consequent ligament ossification, bony erosions, condylar flattening, disk destruction, and reduced range of motion [14].

Ankylosis secondary to AS seems to seldom ensue, and relatively few patients develop such severe degenerative TMJ disease that they require total joint replacement [15]. Only approximately 11 cases have been reported worldwide [1,3], yet subjective symptoms and complaints are frequent and may be present in up to $60 \%$ of cases [13].

When ankylosis occurs, it is an extremely disabling affliction that causes problems with mastication, digestion, speech, appearance, and access to routine dentistry. It also has an impact on the psychological development of the patient with concerns related to an inability to open the mouth $[4,16]$.

Reduced mouth opening, impaired immune system due to immunosuppressive medications, and increased risk of bleeding due to intake of NSAIDs may complicate any routine surgical and/

Correspondence to: Mohammad Hossein Dashti, DMD, Clinical Associate Professor, Postdoctoral Prosthodontics, Department of Restorative Sciences and Biomaterials, Boston University Henry M. Goldman School of Dental Medicine, 100 East Newton Street, Boston, Ma 02118, USA, E-mail: mhdashti@bu.edu

Key words: ankylosing spondylitis, skeletal disorders, orofacial pain, oral rehabilitation, implant-supported prostheses

Received: July 26, 2017; Accepted: August 18, 2017; Published: August 20, 2017 
or restorative procedure $[3,12]$. Treatment of a patient with AS is presented in this report.

\section{Case report}

A 42-year-old white female with the history of AS presented to the primary author with the chief complaint of a diffused pain on the right side of her face.

10 years prior to her first visit, she has had a surgical spinal fixation of her lower back with titanium plates in order to, provide additional support to limit the compression on the affected vertebrae while still offering a wide range of motion. Although she was not disabled by her condition, her movements and her gait were relatively restricted and slow for her age. She also could not sit on the dental chair for extended periods due to the subsequent compression on her lower back. In addition to different dental specialists, she was being seen by a team consisted of two rheumatologists, a physiotherapist, an acupuncturist for her AS. She was also under the care of a psychologist for her diseaserelated anxiety and emotional disturbances.

Her medications included an NSAID; Diclofenac sodium 100 $\mathrm{mg}$ once a day, an antidepressant; Imipramine $100 \mathrm{mg}$ per day, anxiolytics; Clonazepam $0.5 \mathrm{mg}$ per day and propranolol $20 \mathrm{mg}$ per day, and a prophylactic medication for NSAID-associated peptic ulcer; Pantoprazole $40 \mathrm{mg}$ per day. She was also periodically using a range of over the counter pain medications (Ibuprofen $200 \mathrm{mg}$, Acetaminophen $500 \mathrm{mg}$ ) as her pain became persistent.

Extraoral evaluation showed no facial asymmetry or any abnormal findings. Her maximum jaw opening was $45 \mathrm{~mm}$ and there was no sign of deviation from the midline upon opening. Head and neck muscle palpation showed tenderness of the right Temporalis and the internal Pterygoid muscles. All other muscles reacted normally. She had a normal range of cervical movements and no limited opening or any restrictions or interferences in any mandibular movement.

Her existing dental restorations included ceramic crowns with inadequate occlusal contacts and defective margins on all maxillary posterior teeth as well as mandibular left first and second molars. The crowns on her mandibular incisors were esthetically compromised due to their opaque appearance, as compared to their adjacent teeth. She was missing her mandibular right first and second molars which were replaced by an acrylic resin provisional fixed partial denture for the time being (Figure 1).

Her initial treatment plan consisted of stabilization of her musculoskeletal condition by means of an occlusal splint, replacement of her faulty restorations with new fixed provisional restorations, together with the necessary endodontic and periodontal treatments. The definitive treatment would be implemented after complete elimination of pain and discomfort.

Following the insertion of an occlusal splint, the symptoms were alleviated significantly. The occlusal splint was adjusted three times in a four-month period, mainly to improve its retention and comfort. There was no signs of excessive ware on the splint to indicate the presence of a parafunction. At this time, her existing crowns were replaced by fixed provisional crowns, followed by insertion of a new occlusal splint. Her initial response to the temporary restorations was favorable. However, she complained of recurrent pain on the right side of her face a few days later. The patient was referred to a TMJ specialist for further investigation.

The diagnostic protocol included; auscultation for joint sounds, diagnostic local anesthesia to determine whether the pain was dental or non-dental, and antibiotic regimen to evaluate possible dental infection.
None of these tests were diagnostic, according the TMJ specialist. In addition, the TMJ tomography did not reveal any pathologic condition of the condyle, the articular eminence, or any dislocation in an open or closed jaw positions (Figures $2 \& 3$ ). The symptoms were alleviated completely after a new occlusal splint with an increased thickness was fabricated and worn by the patient for 48 hours

With continued stability and comfort, the adjunctive periodontal and endodontic treatments were performed and permanent restorations were constructed and delivered (Figure 4). A new occlusal splint with the similar thickness as the last one was also made. Throughout the five-year postoperative period, the patient was experiencing periods of severe pain and discomfort in different areas of either jaw; mainly, but not limited to, the maxillary right posterior region.

To help in a more precise diagnosis, high definition cone-beam computed tomography(CBCT) was taken. A J-shaped lesion at the apical portion of the distobuccal root of the maxillary right second molar, as seen in the CBCT, raised the possibility of root fracture or an unhealed periapical lesion (Figure 5). This lesion could not be seen on the two-dimensional radiographs taken before. There were also indications of possible communication of the apical portion of the maxillary right first bicuspid with the maxillary sinus, as evidenced by the thickening of the sinus membrane (Figure 6). Mandibular right second bicuspid and second molar did not have any visible fracture, however, the patient's complaint of extreme pain on those

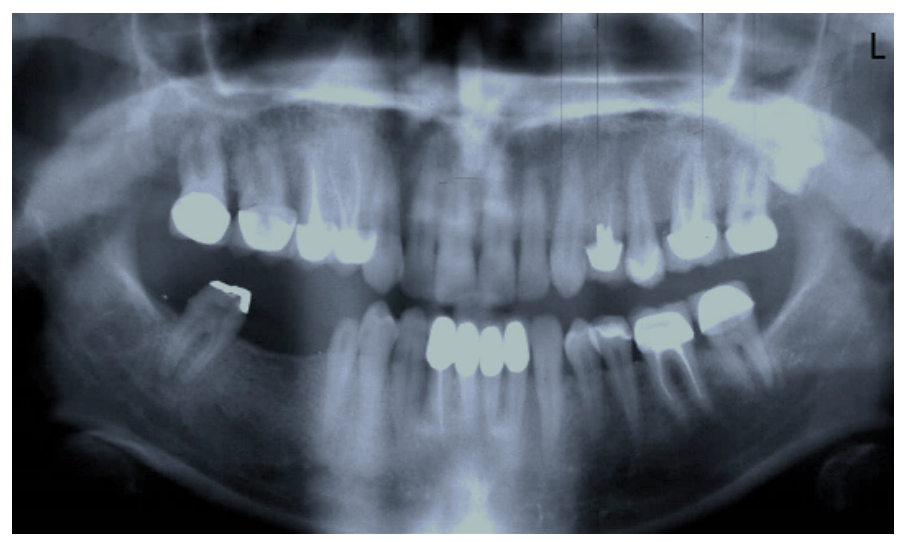

Figure 1. Preoperative panoramic radiograph

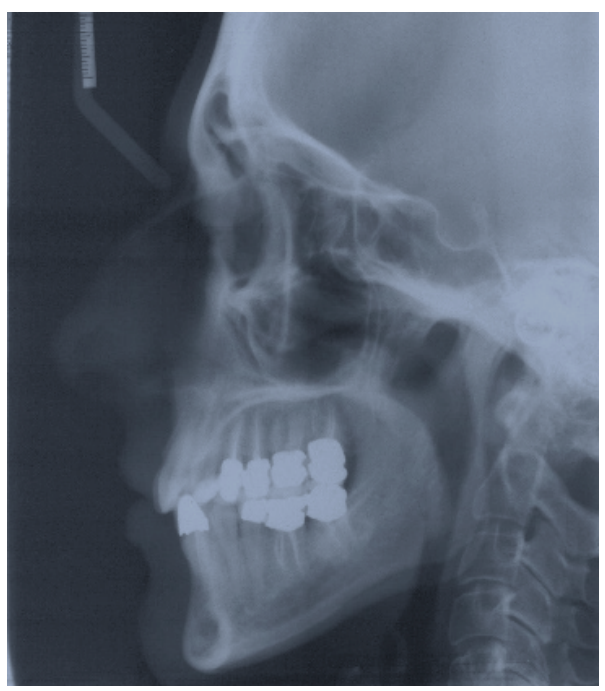

Figure 2. Preoperative lateral cephalogram. 


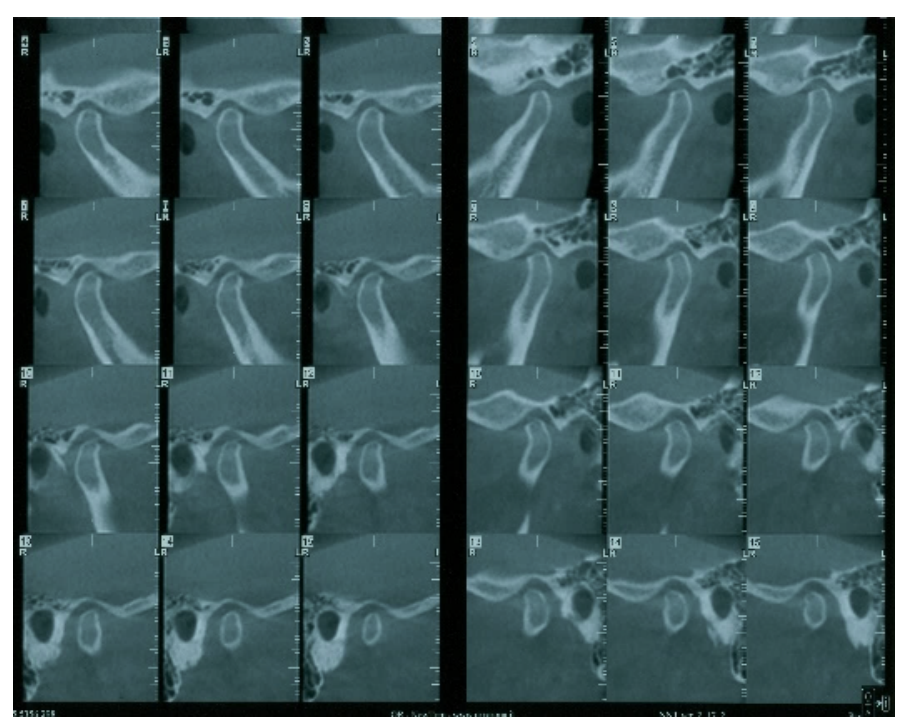

Figure 3. Right and left TMJ tomography.

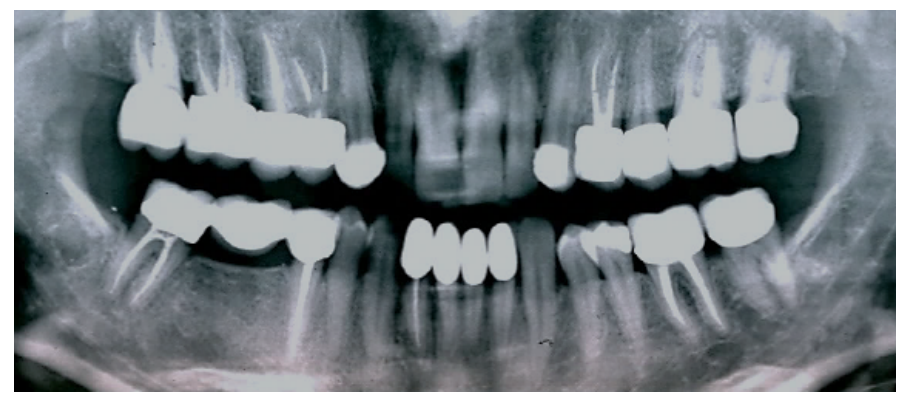

Figure 4. Postoperative radiograph before implant placement.

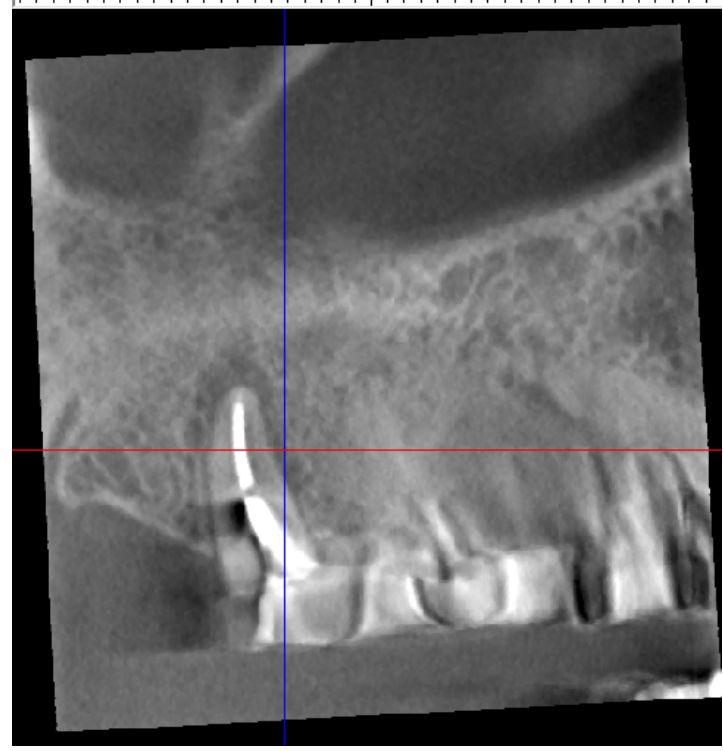

Figure 5. CBCT of the maxillary right second molar showing a J-shaped lesion on distobuccal root.

teeth together with the compromised remaining tooth structure, made their extraction and replacement with the implant-supported fixed prosthesis the most logical treatment option. The pain had been intermittent, lingering, and more profound at night time. The teeth responded negatively to routine tests.
Extraction of the maxillary right posterior teeth were performed in sequence to avoid any unnecessary extraction if the symptoms had been diminished significantly after the extraction of the teeth with the most valid evidence of pathologic conditions (Figure 7). Visual inspection of the extracted teeth with a magnification factor of $3.5 \mathrm{X}$, strengthened the suspicion of root fracture. However, the crack lines were so minute that could have been easily mistaken with variations of normal root morphology.

After the initial healing of the extraction sites, the patient did not have any pain on her right side any more

All maxillary implants (Replace-Select, Noble Biocare) were placed immediately after the extraction of affected natural teeth, but they were loaded with provisional restorations after five months of healing. The mandibular implants (Replace-Select) were placed after the complete healing of the sockets and loaded three months after placement. Porous allograft cancellous bone (Biomet, Tri-State Biologics) was used in conjunction with the immediate placement.

The final restorations were inserted 8 months postsurgically (Figures 8-11). An occlusal splint was fabricated and delivered after the completion of restorative phase (Figure 12). All the final treatments after the initial 5-year period were performed by the last author and his team.

\section{Discussion}

A case of dental rehabilitation of a patient with skeletal disorder, Ankylosing Spondylitis, was presented. Cervical spine stiffness or deformities may make it uncomfortable, or even painful, to sit in the dental chair for extended periods of time. If inflammation of the costovertebral joints of the chest wall occur, limitation of chest expansion could result. Extraarticular manifestations include fibrosis

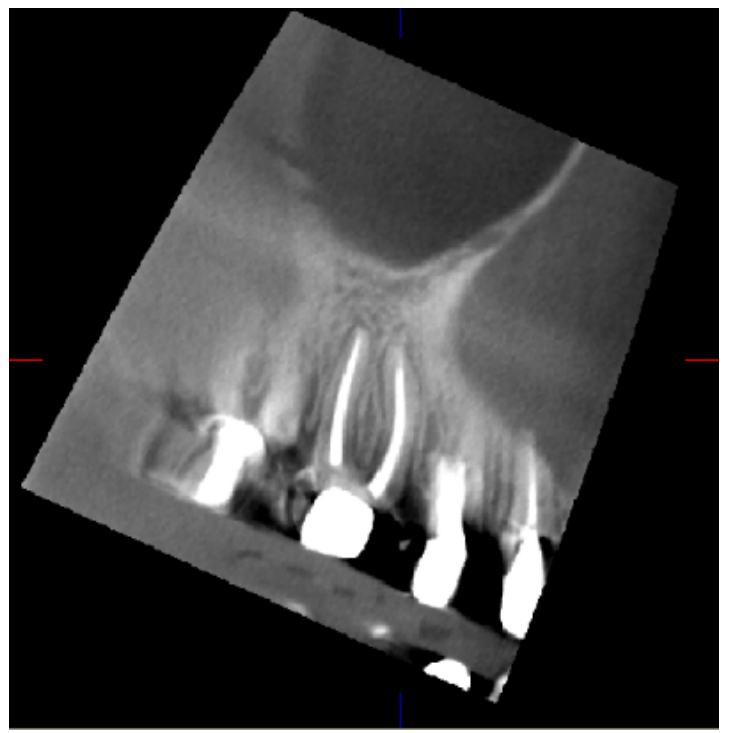

Figure 6. $\mathrm{CBCT}$ of the maxillary right first bicuspid showing its proximity to the maxillary sinus.

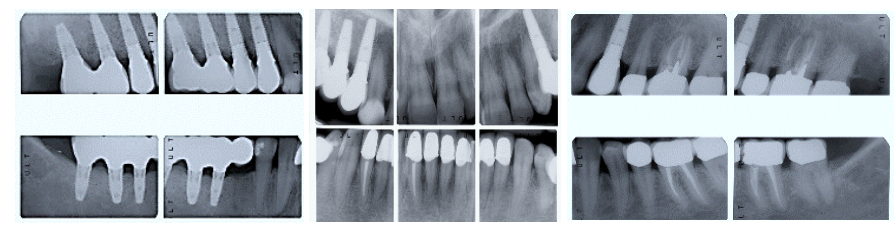

Figure 7. Post-operative radiographs after implant placement 


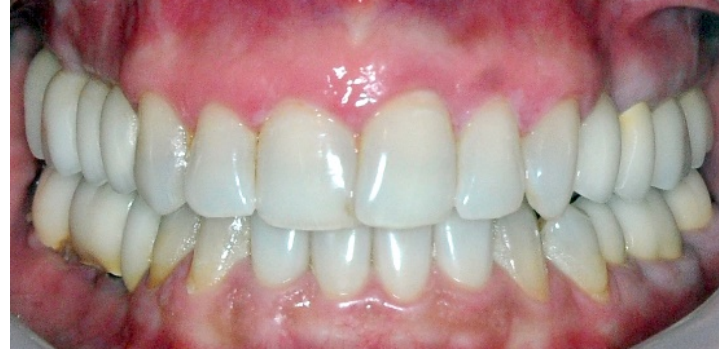

Figure 8. Post-operative clinical view in maximum intercuspal position.

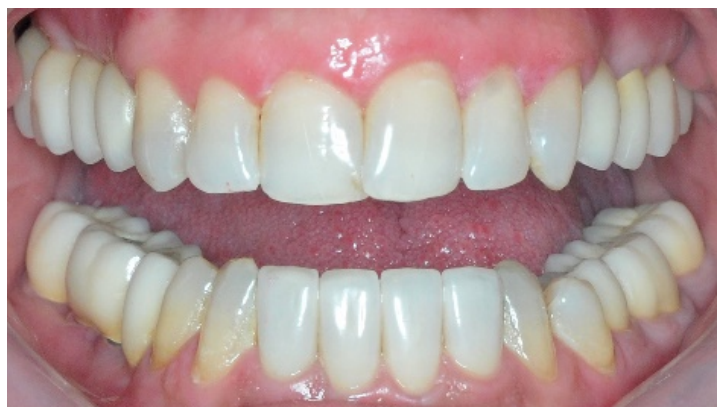

Figure 9. Post-operative clinical view showing the corrected occlusal plane.

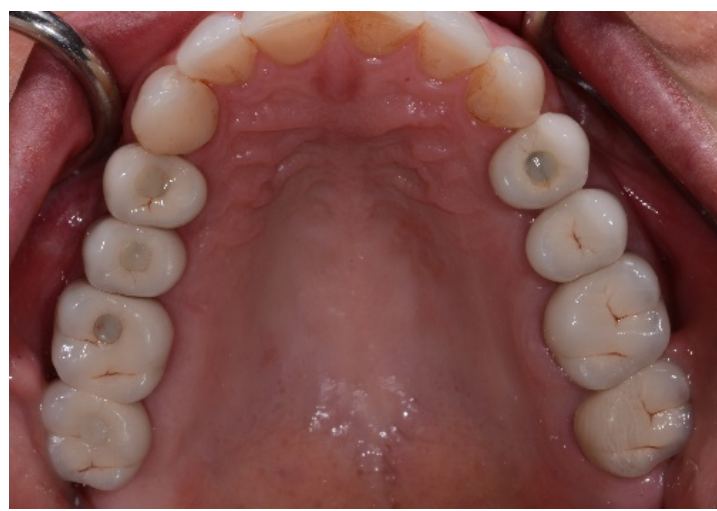

Figure10. Post-operative clinical maxillary occlusal view.

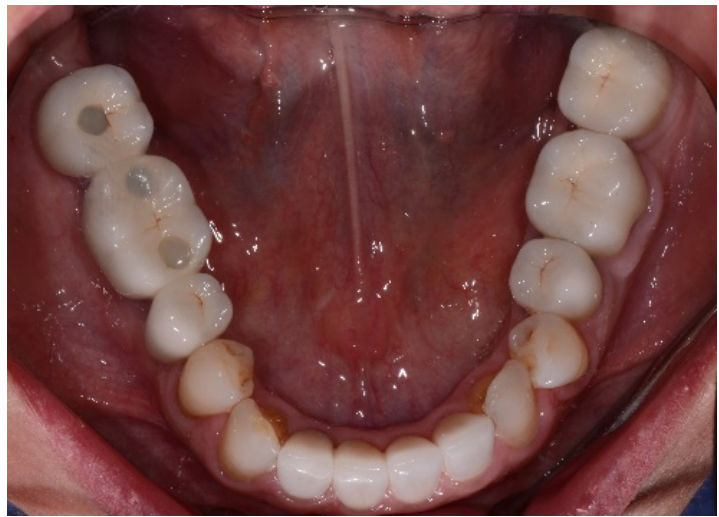

Figure 11. Post-operative clinical mandibular occlusal view

of the lungs. This would force an individual to maintain respiration by labored diaphragmatic movement, making it more difficult to sit still $[4,9]$. Cervical spine involvement may range from slight limitation of neck movement to complete fusion, usually in flexion or bending of the neck. Due to a high incidence of cervical involvement, head and neck

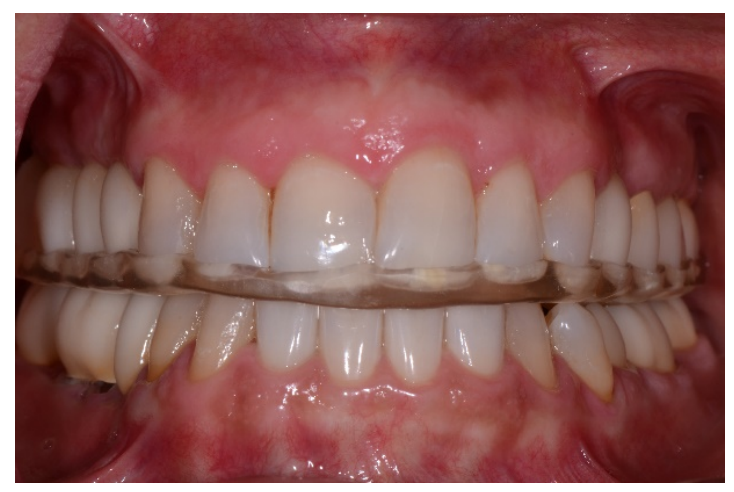

Figure 12. Post-operative clinical view with occlusal splint in place.

support during all the dental procedures is critical [9]. There may be a need for shorter appointments or alternating periods of sitting in the dental chair, interrupted by position changing or standing to alleviate stiffness and pain $[9,17]$.

Throughout the first 5 years of her treatment, the patient had episodes of exacerbation and remission of her pain. She described her pain as "shooting and throbbing" for the maxillary teeth, and "burning sensation" for the mandibular right teeth. Another finding was the constant change in her occlusal contacts, even in the course of a day. Frequently, the shift in the occlusal contacts would result in the mesiodistal movement of some of the abutment teeth and open the proximal contacts which were otherwise meticulously adjusted and delivered. Similar sequence of events have been reported by Okeson [17] and the inflammation of the capsular ligaments (capsulitis) was quoted as a possible cause. The fact that the phenomenon of changing occlusal contacts was not repeated with implant supported prostheses could be due to the relative immobility of these prostheses in the bone, as compared with the tooth-supported restorations. It may also demonstrate the favorable response of her neuromuscular system and, as a result, the reduction of her TMJ inflammation in response to the adjunctive therapies.

Only after all the other attempts to eliminate the patient's pain, which was more noticeable but not limited to the teeth in question, over a period of five years were failed, it was decided to extract and replace them with implants. These attempts included repeated endodontic therapies and microscopic root examinations, periodontal treatments to increase the crown length and to facilitate oral hygiene, and fabrication of multiple post and cores and crowns. To envision the extent of the treatment complications, there were more than 200 clinical visits only with the primary author throughout the initial five year period.

Stafne estimated that between $15-75 \%$ of sinusitis cases have a dental cause [18]. The close proximity of the maxillary sinus to the root of maxillary posterior teeth could result in several endodontic compilations. Maxillary sinus involvement may occur during the endodontic procedure because of the extension of periapical infection into the sinus $[18,19]$. The term "endo-antral syndrome" or "EAS" was coined by Selden for the spread of pulpal disease beyond the confines of the dental supporting tissues into the sinus [20].

A removable partial denture was not a viable option to replace the missing teeth since the patient was not psychologically prepared for a removable prosthesis. In addition, using the adjacent teeth as abutments while the source of pain and discomfort was not precisely detectable, could have added another complexity to the case. 
To the authors' knowledge, there has been only one report of multiple implant failure in patients with AS [21]. It highlights the relationship between ankylosing spondylitis and osteoporosis, although no direct link is made between these conditions and the implant failures. In the present report, implant-supported restorations have been successful and have reduced the symptoms of the patient significantly.

Limited mouth opening has been reported by Davidson and others $[1,3,12]$. Although this particular limitation, was not a major issue throughout the treatment procedures, slow-stretching masseteric exercises were given to the patient prior to those procedures in need of extreme opening of the mandible, such as during endodontic treatment or implant placement in the molar regions [3]. In addition to these considerations and the need for the physician's consent, there are no reported specific requirements before or after implant placement in patients with AS.

Throughout the two-year follow up period after the final prostheses, the patient has been comfortable and has not complained of any pain.

\section{Conclusion}

Dental and orofacial pain may have many different origins and underlying factors. Differential diagnosis is particularly challenging when the patient presents with a systemic skeletal disorder such as ankylosing spondylitis with the potential to affect the head and neck region. While the minimally invasive approach is indicated in these patients, when the affected teeth do not respond positively to conventional restorative treatments, more advanced diagnostic techniques such as CBCT can be instrumental and, if indicated, replacement of the affected teeth with implant prostheses may be a viable alternative.

\section{Acknowledgements}

The authors wish to give their special appreciation to Mrs. Nazila Akhavan, who is also a translator of one of the books in the reference section into Persian language, for her unbending dedication to expand the knowledge of the health professionals regarding the patients with spinal disorders in general, and AS in particular. Without her input, this study would not have been possible. Authors also thank the faculties of the postdoctoral endodontic department at Boston University Henry M Goldman School of Dental Medicine for their expert opinion in the interpretation of the CBCT cuts. Finally, thanks to all the individuals directly or indirectly involved in the management of the patients with AS.

\section{Disclosure}

Presented as a poster presentation at the Academy of Osseointegration, Seattle, Washington, March 2014. It won the second best case study presentation.

\section{References}

1. Felstead AM, Revington PJ (2011) Surgical management of temporomandibular joint ankylosis in ankylosing spondylitis. Int J Rheumatol 2011: 854167. [Crossref]
2. Khan MA (2002) Ankylosing spondylitis: the facts. United Kingdom: Oxford University Press.

3. Mehdizadeh M, Poorsattar BM (2012) Surgical orodental implications in ankylosing spondylitis. Dent Res J (Isfahan) 9: 807-811. [Crossref]

4. Manemi R, Kenchangoudar R, Revington P (2012) Ankylosing spondylitis of temporomandibular joint (TMJ). In: Bruges-Armas J (ed), Clinical and Molecular Advances in Ankylosing Spondylitis. In Tech 2012:15-26.

5. Feldtkeller E, Khan MA, van der Heijde D, van der Linden S, Braun J (2003) Age at disease onset and diagnosis delay in HLA-B27 negative vs. positive patients with ankylosing spondylitis. Rheumatol Int 23: 61-66. [Crossref]

6. Dincer U, Cakar E, Kiralp MZ, Dursun H (2008) Diagnosis delay in patients with ankylosing spondylitis: Possible reasons and proposals for new diagnostic criteria. Clin Rheumatol 27: 457-462.

7. Reveille JD (2006) Major histocompatibility genes and ankylosing spondylitis. Best Pract Res Clin Rheumatol 20: 601-609. [Crossref]

8. Calin A, Porta J, Fries JF, Schurman DJ (1977) Clinical history as a screening test for ankylosing spondylitis. JAMA 237: 2613-2614. [Crossref]

9. Ankylosing spondylitis (AS): Spondylitis Association of America. Internet web site. 2008 June.

10. Helenius LM, Hallinkanen D, Helenius I, Meurman JH, Kononen M, et al. (2005) Clinical and radiographic findings of the temporomandibular joint in patients with various rheumatic diseases. A case-control study. Oral Surg Oral Med Oral Pathol Oral Radiol Endod 99: 455-463. [Crossref]

11. Olivieri I, Salvarani C, Ciancio G, Padula A (2001) Ankylosing spondylitis and undifferentiated Spondyloarthropathies: a clinical review and description of a disease subset with older age at onset. Curr Opin Rheumatol 13: 280-284. [Crossref]

12. Davidson C, Wojtulewski JA, Bacon PA, Winstock D (1975) Temporo-mandibular joint disease in ankylosing spondylitis. Ann Rheum Dis 34: 87-91. [Crossref]

13. Grinin VM, Smirnov AV (1997) Involvement of the temporomandibular joints in Bechterew's disease. Stomatologiia (Mosk) 76: 18-21. [Crossref]

14. Koidis PT, Basli I, Topouzelis N (2009) Ankylosing spondylitis associated with craniomandibular disorder-a combined orthodontic and prosthodontic therapeutic approach. World J Orthod 10: 371-377. [Crossref]

15. Crum RJ, Loiselle RJ (1971) Temporomandibular joint symptoms and ankylosing spondylitis. The Journal of the American Dental Association 83: 630-633.

16. Roychoudhury A, Parkash H, Trikha A(1999) Functional restoration by gap arthroplasty in temporomandibular joint ankylosis a report of 50 cases. Oral Surg Oral Med Oral Pathol Oral Radiol Endod 87: 166-169. [Crossref]

17. Okeson JP (2003) Management of temporomandibular disorders and occlusion. 5th ed. St. Louis: Mosby; 470-471.

18. Nimigian VR, Nimigean V, Maru N, Andressakis D, Balatsouras DG, Danielidis V (2006) The maxillary sinus and its endodontic implications: Clinical study and review. B-ENT 2: 167-175. [Crossref]

19. Maillet M, Bowles WR, McClanahan SL, John MT, Ahmad M (2011) Cone-beam computed tomography evaluation of maxillary sinusitis. J Endod 37: 753-757. [Crossref]

20. Selden HS (1999) Endo-antral syndrome and various endodontic complications. $J$ Endod 25: 389-393. [Crossref]

21. Barker D, Nohl FS, Postlethwaite KR, Smith DG (2008) Case report of multiple implant failure in a patient with ankylosing spondylitis. Eur J Prosthodont Restor Dent 16: 20-23. [Crossref]

Copyright: (C2017 Dashti MH. This is an open-access article distributed under the terms of the Creative Commons Attribution License, which permits unrestricted use, distribution, and reproduction in any medium, provided the original author and source are credited. 